\title{
Inhibition of Colon Carcinoma Cell Migration Following Treatment with Purified Venom from Lesser Weever Fish (Trachinus Vipera)
}

\author{
Myriam Fezaia ${ }^{a, b, c}$ Chaker Slaymid Mossadok Ben-Attia ${ }^{a, b} \quad$ Guido Kroemer ${ }^{e, f, g, h, i, j, k, l}$ \\ Florian Lang ${ }^{c, m}$ Mohamed Jemaàc,n
}

\begin{abstract}
aLaboratory of Biomonitoring of the Environment (LR01/ES14), Bizerte, Faculty of Sciences of Bizerte, ' University of Carthage, Carthage (Tunisia); 'Department of Internal Medicine III, University of Tuebingen, Tuebingen, Germany; dUniversity of Montpellier, Montpellier, eGustave Roussy Comprehensive Cancer Institute, Villejuif, fINSERM, U1138, Paris, 9Equipe 11 labellisée par la Ligue Nationale contre le Cancer, Centre de Recherche des Cordeliers, Paris, hUniversité Paris Descartes/ Paris V, Sorbonne Paris Cité, Paris, 'Université Pierre et Marie Curie/Paris VI, Paris, jMetabolomics and

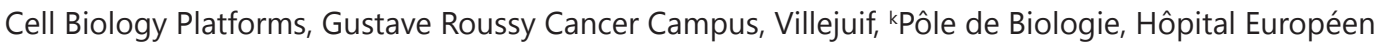
Georges Pompidou, AP-HP, Paris, France; 'Department of Women's and Children's Health, Karolinska University Hospital, Stockholm, Sweden; mDepartment of Molecular Medicine II, Heinrich Heine University Duesseldorf, Germany; nepartment of Laboratory Medicine, Translational Cancer Research, Lund University, Lund, Sweden
\end{abstract}

\section{Key Words}

Lesser weever fish venom - Cell volume - Granularity - Migration - Mitochondrial pathway of apoptosis $•$ p53

\begin{abstract}
Background: Injury by the sting of Lesser weever fish (Trachinus vipera) may lead to severe pain, edema or tissue necrosis. Cellular effects of the venom are still incompletely understood. Previous observations revealed that purified Lesser weever fish venom (LWFV) induces suicidal death of erythrocytes and HCT116 human colon carcinoma cells. The present study addressed the effect of the venom on colon carcinoma cell toxicity, shape and migration both in $\mathrm{p} 53^{+/+}$ and/or p53 $\mathrm{ml}$ LWFV. Cell shape, cell area and circularity were visualized and quantified by fluorescence microscopy. Cell volume, granularity and cells toxicity were assessed via the apoptotic parameters dissipation of mitochondrial inner transmembrane potential, phosphatidylserine surface exposure and cell membrane permeabilization were measured utilizing flow cytometry. Cell migration was evaluated using wound healing assay and two-dimensional migration assay. Results: LWFV treatment was followed by a marked change of cell shape and size, significant decrease of cell area and circularity, significant impairment of cell migration, as well as F. Lang and M. Jemaà share senior co-authorship.

Dr. Mohamed Jemaà and Prof. Dr. Florian Lang

Department of Internal Medicine III, University of Tuebingen,

Gmelinstr. 5, D-72076 Tuebingen (Germany)

E-Mail jemaamohamed@gmail.com / florian.lang@uni-tuebingen.de
\end{abstract}


induction of apoptosis after long exposition. Conclusions: LWFV exposure leads to cell shrinkage, increased granularity, apoptosis and impairment of cell migration, effects presumably contributing to LWFV-induced tissue injury.

(C) 2017 The Author(s)

Published by S. Karger AG, Basel

\section{Introduction}

For defense and for hunting several marine animals are equipped with venoms [1]. Poisonous animals include Trachinus vipera (Lesser weever fish), living in the coastal waters of Mediterranean Sea and Atlantic Ocean [2,3]. Trachinus vipera is the smallest member of the Trachinidae family [4]. The poison is located in dorsal spines of the fish as well as a single spine on each main gill cover [5]. Injury by the spines leads to local erythema, edema and inflammation within few hours up to 14 days [3-8]. The local reaction may be paralleled by nausea, vomiting and headache [9]. Complications may include tissue necrosis [4, 10], Raynaud's Phenomenon [11] and even fatal outcome [5].

Despite those clinical features caused by the weever fish stings, there are no pharmacological studies that investigated the weever fish venom properties. We started working on this venom and we have been the first to show in a previous study the capacity of Lesser Weever Fish Venom (LWFV) to trigger suicidal death of both, erythrocytes and nucleated cells [12].

The present study aimed to define the effects of LWFV in human colon cancer cells. To this end we used the colon cancer cell lines RKO and HCT116 in $\mathrm{p}^{+/ /+}$or $\mathrm{p} 53^{-/}$genotyping condition and we checked cell shape, cell size, cell migration and cell death following 24 to 72 hours of treatment with LWFV.

\section{Materials and Methods}

Venom extraction and dialysis

Specimens of Trachinus vipera were collected along the Cap Bon coast in North-East of Tunisia. The venom was extracted from the dorsal fins of fish (these fins are made of clusters of glandular cells with venom). To that end, fins were crushed 10 minutes in a mixer, and then sonicated at a frequency of $47 \mathrm{kHz}$ during $30 \mathrm{~min}$ at $20^{\circ} \mathrm{C}$. The crushed mixture was centrifuged at $5000 \mathrm{rpm} / 10 \mathrm{~min} / 4^{\circ} \mathrm{C}$. The supernatant was collected for dialysis against MilliQ water using dialysis cellulose membrane of $8 \mathrm{kDa}$ cutoff. The dialysate was filtered through $0.22 \mu \mathrm{m}$, then lyophilized and stored at $-20^{\circ} \mathrm{C}$ until further use.

Cells and culture conditions

Human colon carcinoma WT and p53\% HCT 116 and WT RKO cells were maintained in McCoy's 5A medium supplemented with $10 \%$ fetal calf serum (FCS), 10 mM HEPES buffer, 100 units/mL penicillin G sodium and $100 \mu \mathrm{g} / \mathrm{mL}$ streptomycin sulfate. Cells were seeded onto the appropriate supports (6-, 12- or 96-well plates) $24 \mathrm{~h}$ before the beginning of experiments.

\section{RNA interference}

p53 WT HCT 116 and RKO cells were seeded at low density in 6-well plates and after $24 \mathrm{~h}$ transfected with an unrelated siRNA (siUNR) or with a specific siRNA directed against p53 (SignalSilence p53 siRNA I, \#6231, Cell Signaling Technology, Billerica, MA) by means of lipofectamine RNAiMAX transfection reagent (Thermo Fisher Scientific-Invitrogen), according to the manufacturer's instructions. The following siRNAs were used: 5'-GCCGGUAUGCCGGUUAAGUdTdT- 3'(siUNR).

\section{Immunofluorescence}

Immunofluorescence microscopy was performed according to conventional procedures. Briefly, cells were fixed with $100 \%$ methanol for 10 minutes at $-20^{\circ} \mathrm{C}$ and then washed with PBS. Hoechst $33342(1 \mu \mathrm{g} /$ $\mathrm{mL}$ ) was used for nuclear staining (Sigma-Aldrich). Monoclonal antibodies against $\beta$-tubulin, $\gamma$-tubulin or actin (Sigma-Aldrich) were used. Revelation was performed with the appropriate Alexa Fluor conjugated 


\section{Cellular Physiology Cell Physiol Biochem 2017;41:2279-2288

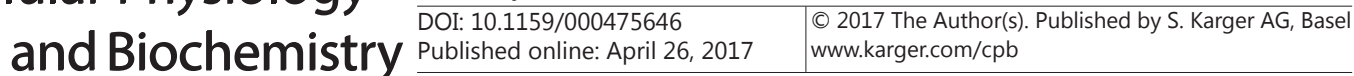 \\ Fezai et al.: Effect of Lesser Weever Fish Venom on Cancer Cells}

secondary antibodies (Thermo Fisher Scientific-Invitrogen). Microphotographs with the objective 20 and 40 were taken for analysis and count. Images were analyzed to determine the cell area and circularity with the open source software Image J (freely available from the National Institute of Health, Bethesda, MD, USA at the address http://rsb.info.nih.gov/ij/).

\section{Flow cytometry}

For the quantification of cell size and granularity, cells were incubated under the respective experimental condition. For the quantification of apoptotic features (Plasma membrane integrity, Phosphatidylserine outer membrane exposure and mitochondrial transmembrane potential $(\Delta \psi \mathrm{m})$, respectively) live cells were collected and stained with $1 \mu \mathrm{g} / \mathrm{mL}$ propidium iodide (PI, which only incorporates into dead cells, from Sigma-Aldrich), $40 \mathrm{nM}$ 3,3'-dihexyloxacarbocyanine iodide (DiOC6(3), a $\Delta \psi \mathrm{m}$-sensitive dye) (Molecular probes-Invitrogen, Eugene, OR, USA) or with Annexin-V-FITC (1:200 dilution; ImmunoTools, Friesoythe, Germany) for $30 \mathrm{~min}$ at $37^{\circ} \mathrm{C}$ under protection from light. Cytofluorometric acquisitions were performed by means of a FACSCalibur (BD Biosciences) cytofluorometer, while data analysis was conducted using the CellQuestTM (BD Biosciences) and the Kaluza (Beckman Coulter) software [13, 14].

\section{Wound healing assay}

For wound-healing assay, scratches were performed, with sterile $200 \mu \mathrm{l}$ tips, on confluent cell monolayers and monitored every $24 \mathrm{~h}$ by phase light microscopy. The covered cell free area quantification was performed using the software Image J.

\section{Two-dimensional cell migration assay}

The two-dimensional cell migration assay was performed using the Oris ${ }^{\mathrm{TM}}$ Cell Migration Assays (Platypus Technologies, Madison, USA) according to the manufacturer's instructions. Briefly, cells were seeded ( $2 \times 10^{4}$ cells per well) into a 96-well plate with "silicone stopper". After complete adhesion, (overnight culture) stoppers were removed and cells were washed and cultured for $24 \mathrm{~h}$ or $48 \mathrm{~h}$ allowing the migration into the free area zone, then cells were fixed with 4\% PFA in PBS and stained with phalloidinFITC (for actin staining) [13]. Microphotographs with the objective 5 were taken for analysis and count.

\section{Statistics}

Data are expressed as arithmetic means \pm SEM. Statistical analysis was made using ANOVA with Tukey's test as post-test. $\mathrm{n}$ denotes the number of different independent experiments .

\section{Results}

The Trachinus vipera venom changes the cells shape in vitro

In order to uncover the effect of Lesser weever fish venom (LWFV) on human colon carcinoma cells in vitro, HCT116 cells were treated with $500 \mu \mathrm{g} / \mathrm{ml}$ LWFV for 24 and 48 hours. As illustrated in Fig.1, the treatment was followed by marked alterations of cell shape. Light microphotographs (Fig1A) show a dramatic cell shape change, cells retraction and a formation of two to three anchoring points. $\beta$ and $\gamma$-tubulin staining (Fig1B) and actin staining (Fig2A) confirmed the alteration of cell cytoskeleton architecture. Moreover, Image analysis revealed that the shape change was further paralleled by a significant decrease of cell surface area (Fig. 2A and B) and a significant decrease of circularity (Fig. 2A and C).

To test whether the observed cells shape rearrangement is p53 dependent or not, we decided to use both WT and p53\% HCT116 cells, and to use in addition a specific siRNA against p53 on HCT116 and RKO cells. Cells were transfected with siRNA UNR or p53 and after 24 hours treated or not with LWFV for 48 hours. In parallel, WT and p53\% were treated or not with LWFV.

Forward scatter determined by flow cytometry was taken as measure of cell size. As illustrated in Fig. 3A, B, C and D, LWFV treatment was followed by a significant decrease of average forward scatter, an observation reflecting cell shrinkage. The cell shrinkage was the same in $\mathrm{p}^{+/++}$cells and $\mathrm{p} 53^{\%}$ cells. Moreover, LWFV treatment significantly increased the 
Fig. 1. Trachinus vipera venom changes cell shape. A. Phase contrast micrograph of colon HCT116 carcinoma cells after 24 hours incubation in the absence (control) or presence (treated) of Lesser weever fish venom (LWFV). Scale bar $=10$ $\mu$ m. B. $\beta$-tubulin, DNA (Hoechst) and $\gamma$-tubulin staining of HCT116 colon carcinoma cells after prior 24 hours incubation in the absence (control) or presence (treated) of Lesser weever fish venom (LWFV). Scale bar $=10 \mu \mathrm{m}$.

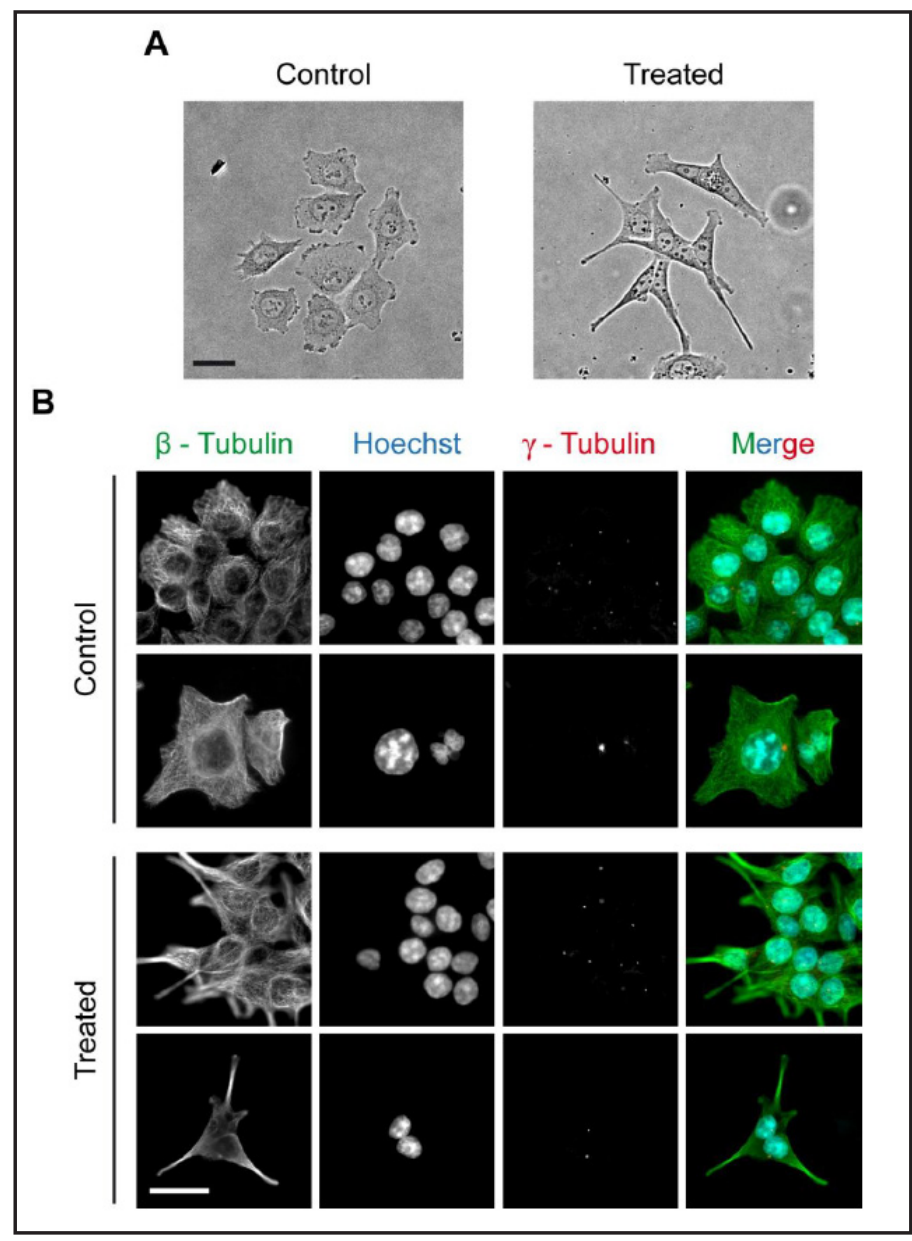

B

C

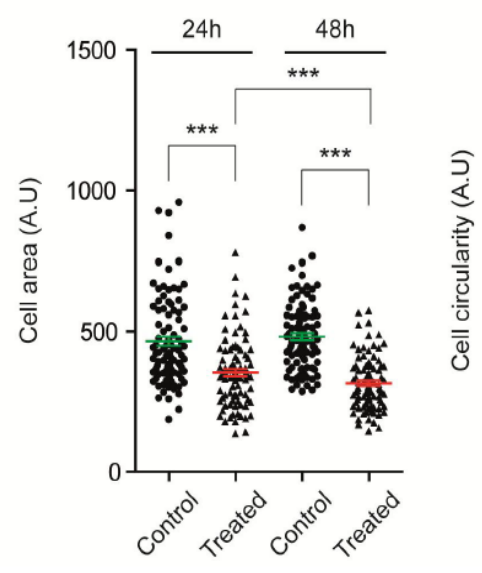

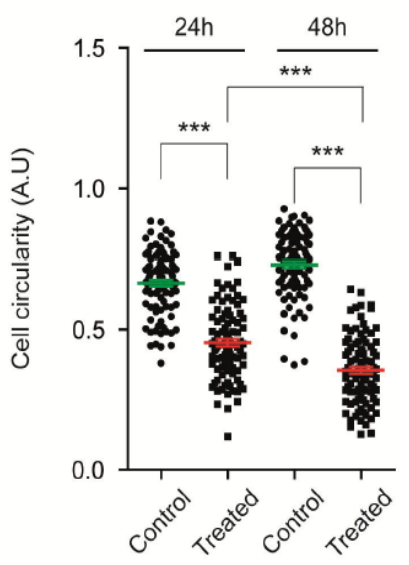

Fig. 2. Trachinus vipera venom decreases cell area and cell circularity. A. DNA (Hoechst) and actin staining of HCT116 colon carcinoma cells after prior 24 or 48 hours incubation in the absence (control) or presence (treated) of Lesser weever fish venom (LWFV). Scale bar $=10 \mu \mathrm{m}$. B and C. Cell area (B) and cell circularity (C) of HCT116 colon carcinoma cells after prior 24 or 48 hours incubation in the absence (control) or presence (treated) of Lesser weever fish venom (LWFV). ${ }^{* * *}(p<0.001)$ indicates significant difference from the absence of venom (ANOVA). 
A

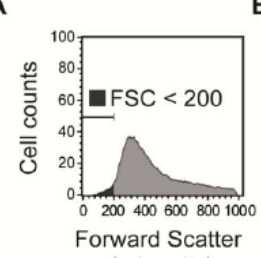

C

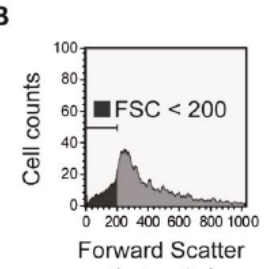

(rel. units)

\section{E \\ G}
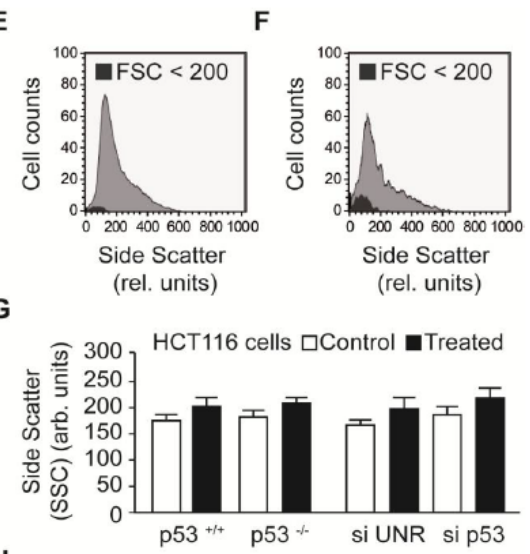

H

D

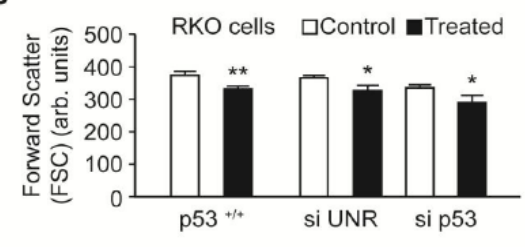

I

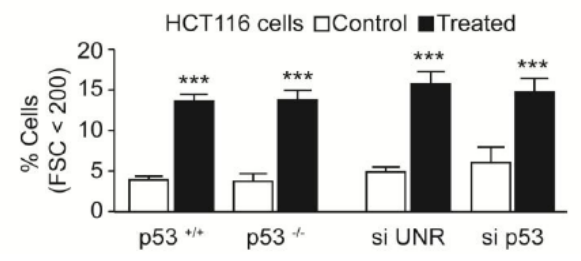

$\mathbf{J}$

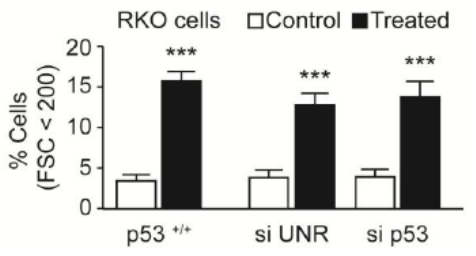

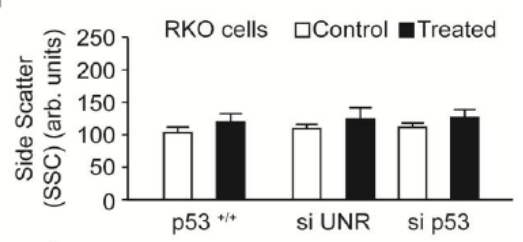

Fig. 3. Trachinus vipera venom decreases forward scatter and increases side scatter in flow cytometry. A and B. Original histograms of forward scatter of HCT116 colon carcinoma cells after prior 48 hours incubation in the absence (A) or presence (B) of Lesser weever fish venom (LWFV). Percentage of cells FSC $<200$ are colored in dark grey. C. Arithmetic means \pm SEM $(n=3)$ of the HCT116 cells $\left(\mathrm{p} 53^{+/+}, \mathrm{p} 53^{\%^{-}}, \mathrm{p} 53^{+/+}\right.$transfected with siUNR and $\mathrm{p}^{+/+}$transfected with sip53, respectively), forward scatter (FSC) following incubation for 48 hours without (white bar) or with (black bars) LWFV. D. Arithmetic means \pm SEM ( $n=3$ ) of the RKO cells (p53+/+, p53 $3^{+/+}$transfected with siUNR and p53//+ transfected with sip53, respectively), forward scatter (FSC) following incubation for 48 hours without (white bar) or with (black bars) LWFV. E and F. Original histograms of side scatter of HCT116 colon carcinoma cells after prior 48 hours incubation in the absence (E) or presence (F) of LWFV. Cells with FSC $<200$ are colored in dark grey. G. Arithmetic means \pm SEM $(n=3)$

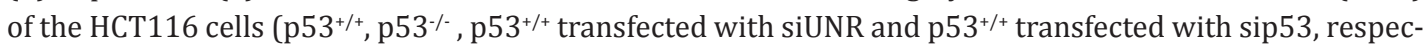
tively), side scatter (SSC) following incubation for 48 hours without (white bar) or with (black bars) LWFV. H. Arithmetic means \pm SEM $(n=3)$ of the RKO cells $\left(\mathrm{p} 53^{+/+}, \mathrm{p} 53^{+/+}\right.$transfected with siUNR and p53 $3^{+/+}$transfected with sip53, respectively), side scatter (SSC) following incubation for 48 hours without (white bar) or with (black bars) LWFV. I. Percentage of the HCT116 cells (p53 ${ }^{+/+}, \mathrm{p} 53^{-/}, \mathrm{p} 53^{+/+}$transfected with siUNR and $\mathrm{p}^{+/+}$transfected with sip53, respectively), with $\mathrm{FSC}<200$ following incubation for 48 hours without (white bar) or with (black bars) LWFV. J. Percentage of the RKO cells (p53 ${ }^{+/+}$, p53 $3^{+/+}$transfected with siUNR and $\mathrm{p}^{+/+}$transfected with sip53, respectively), with FSC $<200$ following incubation for 48 hours without (white bar) or with (black bars) LWFV. ${ }^{*}(p<0.05),{ }^{* *}(p<0.01),{ }^{* * *}(p<0.001)$ indicates significant difference from the absence of venom (ANOVA).

percentage of shrunken cells (Fig. 3I and J). Granularity was quantified by measurement of side scatter. As shown in Fig. 3E, F, G and H, LWFV treatment was followed by an increase of side scatter and thus granularity. All these observations confirm that the cell shape change was independent from p53 after LWFV treatment. 

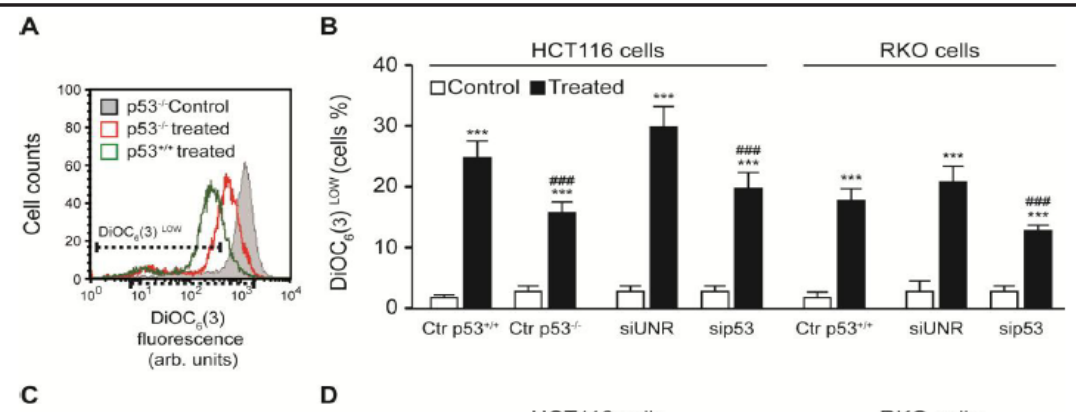

C

D
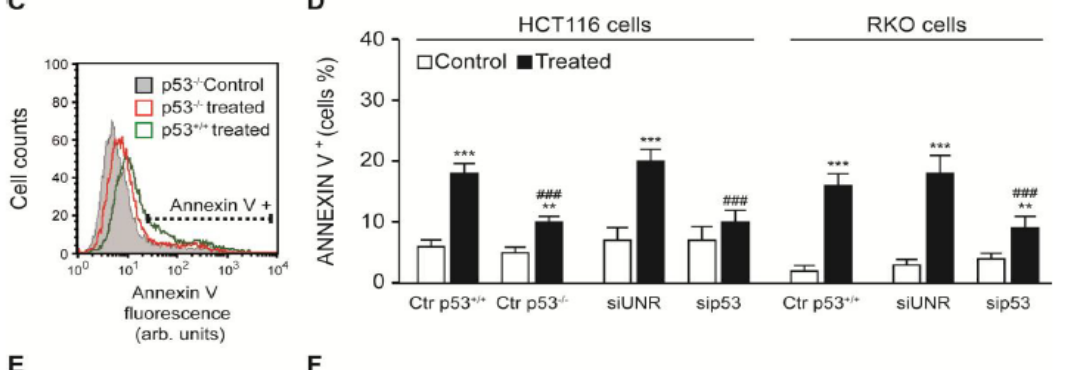

E

$\mathbf{F}$
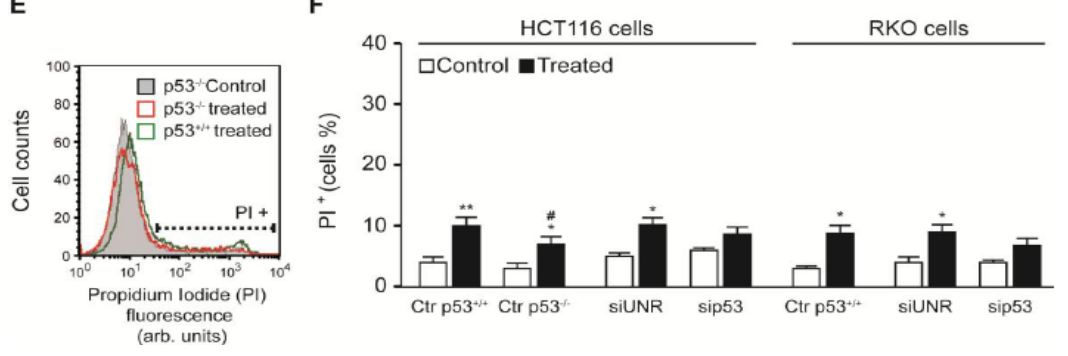

Fig. 4. Trachinus vipera venom kills cells via the mitochondrial pathway of apoptosis. A. Original histograms of the mitochondrial transmembrane potential $\left(\Delta \psi_{\mathrm{m}}\right)$ sensor $\operatorname{DiOC}_{6}(3)$ uptake in HCT116 cells after $72 \mathrm{~h}$ of treatment. Grey area represents p53\% control cells, red line represents p53\% treated cells while green line represents $\mathrm{p} 3^{+/+}$treated cells. B. Arithmetic means \pm SEM $(\mathrm{n}=3)$ of the $\operatorname{DiOC}_{6}(3)$ uptake in HCT116 cells (p53 $3^{+/+}, \mathrm{p} 53^{-/}, \mathrm{p} 53^{+/+}$transfected with siUNR and $\mathrm{p} 53^{+/+}$transfected with sip53, respectively) and RKO cells $\left(\mathrm{p} 53^{+/+}, \mathrm{p} 53^{+/+}\right.$transfected with siUNR and $\mathrm{p} 53^{+/+}$transfected with sip53, respectively). C. Original histograms of annexin-V-binding in HCT116 cells after $72 \mathrm{~h}$ of treatment. Grey area represents p53\% control cells, red line represents $\mathrm{p} 53^{-/}$treated cells while green line represents $\mathrm{p} 53^{+/+}$treated cells. D. Arithmetic means \pm SEM $(\mathrm{n}=3)$ of the annexin-V-binding in HCT116 cells $\left(\mathrm{p} 53^{+/+}, \mathrm{p} 53^{\%}, \mathrm{p} 53^{+/+}\right.$transfected with siUNR and

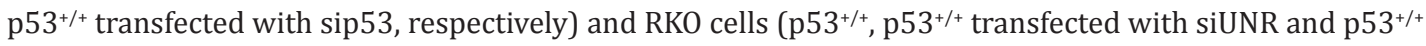
transfected with sip53, respectively). E. Original histograms of the Propidium Iodide PI incorporation in HCT116 cells after $72 \mathrm{~h}$ of treatment. Grey area represents $\mathrm{p} 53^{\%}$ control cells, red line represents p53\% treated cells while green line represents $\mathrm{p} 53^{+/+}$treated cells. F. Arithmetic means \pm SEM $(n=3)$ of the Propidium Iodide PI incorporation in HCT116 cells $\left(\mathrm{p} 53^{+/+}, \mathrm{p} 53^{-\%}, \mathrm{p} 53^{+/+}\right.$transfected with siUNR and p53 $3^{+/+}$transfected with sip53, respectively) and RKO cells (p53 $3^{+/+}, \mathrm{p}^{2} 3^{+/+}$transfected with siUNR and $\mathrm{p}^{+/ /+}$transfected with sip53, respectively). ${ }^{*}(p<0.05),{ }^{* *}(p<0.01)$ and ${ }^{* * *}(p<0.001)$ indicates significant difference from the absence of venom, $\#(p<0.05)$ and \#\#\#( $p<0.001)$ indicates significant difference from $\mathrm{p}^{2 / /+}$ (ANOVA).

The Trachinus vipera venom triggers the mitochondrial pathway of apoptosis in colon cancer cells

To investigate LWFV toxicity in human colon cancer cells, we treated both HCT116 and

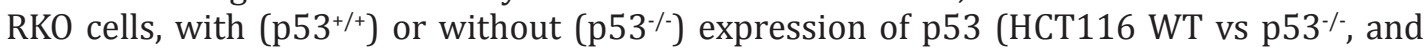
HCT116 WT or RKO WT transfected with siUNR or siP53) for 72h. The cells were then stained with the mitochondrial transmembrane potential $\left(\Delta \psi_{\mathrm{m}}\right)$ sensor $\mathrm{DiOC}_{6}(3)$, annexin-V for the phosphatidylserine exposure or the vital dye propidium iodide (PI) to check the membrane integrity. As illustrated in Fig. 4A and B, LWFV treatment induced a significant loss of the 


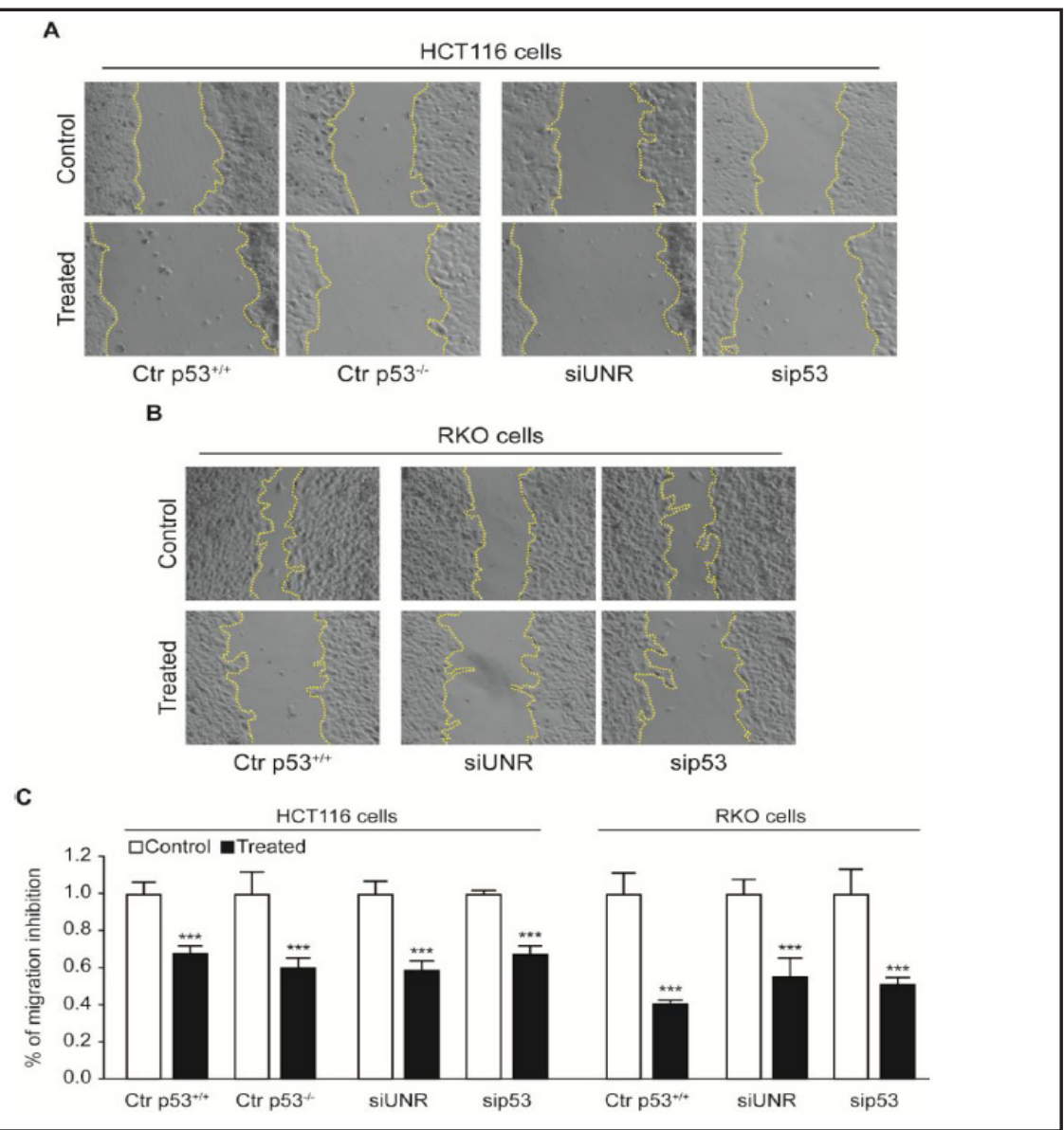

Fig. 5. Trachinus vipera venom inhibits cell migration in wound healing assay. A. Representative microphotographs of HCT116 cells (p53\%/+, p53\% , p53 $3^{+/+}$transfected with siUNR and p53 $3^{+/+}$transfected with sip53, respectively) grown to confluency, following scratch with pipet tips and subsequent incubation for 24 hours in the absence (control) or presence (treated) of lesser weever fish venom (LWFV). The yellow broken lines delimit the cell-free area. B. Representative microphotographs of RKO cells (p53\%+, p53\% transfected with

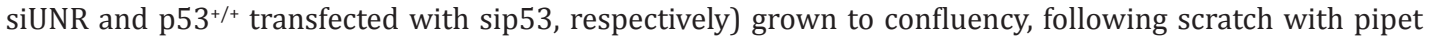
tips and subsequent incubation for 24 hours in the absence (control) or presence (treated) of lesser weever fish venom (LWFV). The yellow broken lines delimit the cell-free area. C. Arithmetic means \pm SEM $(n=3)$ of $\%$ migration inhibition of HCT116 cells (p53 $3^{+/+}, \mathrm{p} 53^{\%}, \mathrm{p} 53^{+/+}$transfected with siUNR and p53 ${ }^{+/+}$transfected with sip53, respectively) and RKO cells (p53/+, p53\% transfected with siUNR and p53 ${ }^{+/+}$transfected with sip53, respectively) after grown to confluency, following scratch with pipet tips and subsequent incubation for 24 hours in the absence (control) or presence (treated) of lesser weever fish venom (LWFV). $* * *(p<0.001)$ indicates significant difference from the absence of venom (ANOVA).

mitochondrial transmembrane potential, pointing to an early stage of the intrinsic apoptosis pathway. The translocation of phosphatidylserine in treated cells confirms the apoptosis as a cell death subroutine (Fig4C and D). The PI incorporation was significantly higher in treated cells than control cells (Fig4E and F) confirming the toxic effect of LWFV on colon cancer cells. Interestingly, the loss of mitochondrial potential was higher than phosphatidylserine translocation and PI incorporation (+/- 20\%, 10\% and 5\% respectively), this confirms that treated cells at 72 hours are in the early stage of mitochondrial apoptosis pathway characterized by a profound loss of mitochondrial transmembrane potential coupled with cell membrane scrambling and cell permeability. The $\mathrm{p} 53^{\%}$ cells were less sensitive to treatment than $\mathrm{p} 53^{+/+}$. 
A

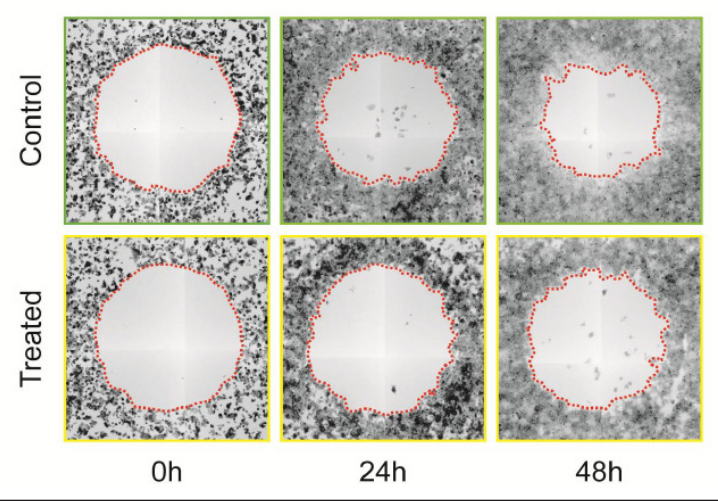

B

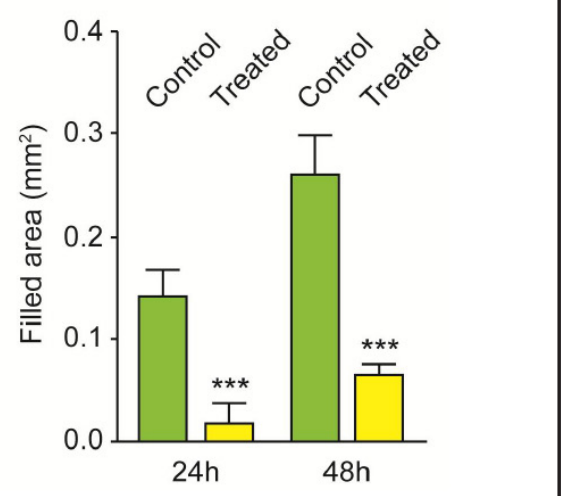

Fig. 6. Trachinus vipera venom inhibits cell migration in two-dimensional migration assay. A. Representative microphotographs of HCT116 colon carcinoma cells in a two-dimensional migration assay using the Oris $^{\mathrm{TM}}$ cell assay. Cells were allowed to migrate for 24 hours or 48 hours after the removal of cell seeding stoppers and treatment with venom, fixed and stained with phalloidin-FITC to evaluate their motile potential. Red broken lines show the empty migration zone. B. Arithmetic means \pm SEM $(n=4)$ of area covered with HCT116 cells in a two-dimensional migration assay following incubation for 24 hours or 48 hours in the absence (control) or presence (treated) of lesser weever fish venom (LWFV). ${ }^{* * *}(p<0.001)$ indicates significant difference from the absence of LWFV (ANOVA).

The Trachinus vipera venom inhibits colon cancer cell migration

To determine the effect of LWFV treatment on cell migration, migration was quantified in a first experimental approach utilizing a 24 hours wound-healing assay on HCT116 and RKO cells in both p53 $3^{++}$and p53\% cells. As illustrated in Fig. 5, the decrease of cell free area was significantly delayed following LWFV treatment. In the HCT116 cells the \% of antimigration effect was about $60 \%$ while in the RKO cells about 50\%. The p53 loss did not influence the anti-migration effect of LWFV. In a second experimental approach, migration was quantified utilizing a two-dimensional migration assay from $\mathrm{Oris}^{\mathrm{TM}}$ on $\mathrm{p5} 3^{+/+}$HCT116 cells. As illustrated in Fig. 6, the decrease of cell free area was again significantly delayed following LWFV treatment.

\section{Discussion}

The present observations reveal that Lesser Weever Fish Venom (LWFV) treatment of human colon cancer cells results in marked changes of cell shape with significant decrease of cell area, circularity and cell size due to the reorganization of the cytoskeletal proteins actin and tubulin. Moreover, LWFV treatment significantly reduces cell migration after 24 to 48 hours of treatment as showed by the wound-healing assay and the normalized test of cell seeding stopper from Oris $^{\mathrm{TM}}[13]$.

An extended exposure to LWFV (72 hours) induces cell death via the mitochondrial pathway of apoptosis. Indeed, the treated cells lost the mitochondrial potential, the early signal of the irreversible pathway of intrinsic caspase dependent apoptosis $[15,16]$, this phase is followed by phosphatidylserine translocation to the outer membrane of the cells before cell membrane permeabilization [17].

p53 is the most frequently mutated gene in human cancers $[18,19]$. We investigated thus the effect of the treatment on p53\% cells. The loss of p53 function confers a death resistance to the treatment in colon cancer cells. Indeed, p53 is the major mediator of the cellular response to stress, p53 stimulates the execution of apoptosis via the transactivation of several proapoptotic genes [20] or physical interactions on the mitochondrial outer

\section{KARGER}




\section{Cellular Physiology Cell Physiol Biochem 2017;41:2279-2288

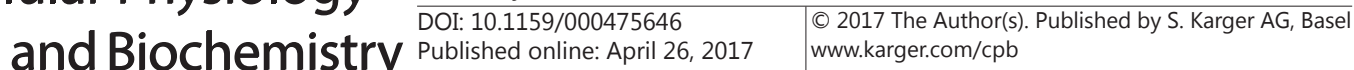 \\ Fezai et al.: Effect of Lesser Weever Fish Venom on Cancer Cells}

membrane permeabilization regulators [21]. Consequently, p53\% cells are notoriously resistant against the induction of apoptosis.

Recent studies point to the potential role of p53 in the control of cell migration and shape [22-24]. We compared the effect of the LWFV on HCT116 and RKO cells in both p53 $3^{+/+}$ and p53\% cells and found that the loss of p53 does not influence the effects of LWFV on cell shape or migration.

LWFV is a complex mixture of diverse large and small molecules, containing kinin or kinin like proteins, enzymes, peptides, serotonin, adrenaline, noradrenaline, and histamine with a wide spectrum of biological activities [2,25]. The observed effects are thus the result of a single component or the composite action of several LWFV components. Further experimental effort is needed in order to uncover the component(s) of LWFV responsible for the observed effects.

In conclusion, treatment of colon cancer cells with LWFV is followed by marked change of cell shape and cell size and substantial impairment of cancer cell migration independently of p53. Moreover, extended exposure to LWFV kills colon cancer cells via the mitochondrial pathway of apoptosis. Those effects could contribute to tissue injury following sting of lesser weever fish and by the same token may have therapeutic potential in the treatment of cancer.

Based on these findings, it may be interesting to launch a large physicochemical study for the identification and characterization of LWFV component(s) that may be effective against tumor growth and metastasis. One of the challenges will be to identify the venom fraction responsible for each effect and then start the drug discovery process.

\section{Acknowledgments}

We are indebted to Bert Vogelstein for WT and TP53\% HCT116 cells. We thank Khaled Hached and Maria Castedo for critical discussions and comments. This work is supported by the Tunisian Ministry of Higher Education and Scientific Research, the Deutsche Forschungsgemeinschaft and the Open Access Publishing Fund of Tübingen University.

\section{Disclosure Statement}

The authors declare no conflict of interest.

\section{References}

Balhara KS, Stolbach A: Marine envenomations. Emerg Med Clin North Am 2014;32:223-243.

Bonnet MS: The toxicology of Trachinus vipera: the lesser weeverfish. Br Homeopath J 2000;89:84-88.

Vasconcelos R, Prista N, Cabral H, Costa MJ: Feeding ecology of the lesser weever, Echiichthys vipera

(Cuvier, 1829), on the western coast of Portugal. Journal of Applied Ichthyology 2004;20:211-216.

Duran FY, Duran Ö: Weever Fish Sting: An Unusual Problem JAEM 2014;13:2.

Davies RS, Evans RJ: Weever fish stings: a report of two cases presenting to an accident and emergency department. J Accid Emerg Med 1996;13:139-141.

Cain D: Weever Fish Sting - an Unusual Problem. British Medical Journal 1983;287:406-407.

Lopacinski B, Bak M, Fiszer M, Czerniak P, Krakowiak A: [Poisoning with weever fish venom: a case report]. Przegl Lek 2009;66:464-465.

8 Mulcahy DM, Devitt A, Shannon F, Reidy D, Callagy G, Walsh M: Case report: Weever fish sting--an unusual cause of foot pain. Ir J Med Sci 1996;165:153-154.

9 ERYILMAZ M, DURUSU M, MENTES MÖ, YIGIT T, ZEYBEK N, ÖNER K: Envenomation Caused by Weever Fish. TURK J EMERG MED 2006;6:3. 


\section{Cellular Physiology Cell Physiol Biochem 2017;41:2279-2288

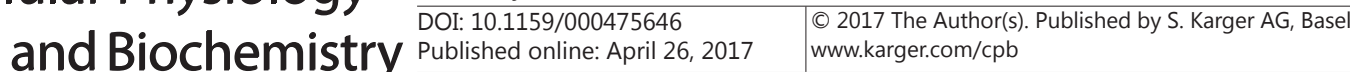

10 Dehaan A, Ben-Meir P, Sagi A: A "scorpion fish" (Trachinus vipera) sting: fishermen's hazard. Br J Ind Med 1991;48:718-720.

11 Carducci M, Mussi A, Leone G, Catricala C: Raynaud's phenomenon secondary to weever fish stings. Arch Dermatol 1996;132:838-839.

-12 Fezai M, Slaymi C, Ben-Attia M, Lang F, Jemaa M: Purified Lesser weever fish venom (Trachinus vipera) induces eryptosis, apoptosis and cell cycle arrest. Sci Rep 2016;6:39288.

-13 Jemaa M, Manic G, Lledo G, Lissa D, Reynes C, Morin N, Chibon F, Sistigu A, Castedo M, Vitale I, Kroemer G, Abrieu A: Whole-genome duplication increases tumor cell sensitivity to MPS1 inhibition. Oncotarget 2016;7:885-901.

14 Jemaa M, Mischitelli M, Fezai M, Almasry M, Faggio C, Lang F: Stimulation of Suicidal Erythrocyte Death by the CDC25 Inhibitor NSC-95397. Cell Physiol Biochem 2016;40:597-607.

15 Zamzami N, Kroemer G: Apoptosis: mitochondrial membrane permeabilization--the (w)hole story? Curr Biol 2003;13:R71-73.

16 Kroemer G, Reed JC: Mitochondrial control of cell death. Nat Med 2000;6:513-519.

17 Ravichandran KS, Lorenz U: Engulfment of apoptotic cells: signals for a good meal. Nat Rev Immunol 2007;7:964-974.

18 Hollstein M, Rice K, Greenblatt MS, Soussi T, Fuchs R, Sorlie T, Hovig E, Smith-Sorensen B, Montesano R, Harris CC: Database of p53 gene somatic mutations in human tumors and cell lines. Nucleic Acids Res 1994;22:3551-3555.

19 Hainaut P, Hollstein M: p53 and human cancer: the first ten thousand mutations. Adv Cancer Res 2000;77:81-137.

20 Beckerman R, Prives C: Transcriptional regulation by p53. Cold Spring Harb Perspect Biol 2010;2:a000935.

-21 Galluzzi L, Morselli E, Kepp 0, Vitale I, Pinti M, Kroemer G: Mitochondrial liaisons of p53. Antioxid Redox Signal 2011;15:1691-1714.

22 Gadea G, Lapasset L, Gauthier-Rouviere C, Roux P: Regulation of Cdc42-mediated morphological effects: a novel function for p53. EMBO J 2002;21:2373-2382.

-23 Gadea G, Roger L, Anguille C, de Toledo M, Gire V, Roux P: TNFalpha induces sequential activation of Cdc42- and p38/p53-dependent pathways that antagonistically regulate filopodia formation. J Cell Sci 2004;117:6355-6364.

24 Roger L, Gadea G, Roux P: Control of cell migration: a tumour suppressor function for p53? Biol Cell 2006;98:141-152.

25 Russell FE: Weever fish sting: the last word. Br Med J (Clin Res Ed) 1983;287:981-982. 